\title{
Breast Nevus
}

National Cancer Institute

\section{Source}

National Cancer Institute. Breast Nevus. NCI Thesaurus. Code C54658.

A benign melanocytic nevus that arises from the breast skin. 